MBER WORKING PAPER SERIES

\title{
SPECULATIVE HYPERINFLATIONS IN MAXIMIZING
} MODELS: CAN WE RULE THEM OUT?

Maurice Obstfeld

Kenneth Rogoff

Working Paper No. $\underline{85}$

NATIONAL BUREAU OF ECONOMIC RESEARCH 1050 Massachusetts Avenue

Cambridge MA 02138

February 1982

The research reported here 18 part of the NBER's research program In International Studies. Any opinions expressed are those of the authors and not those of the National Bureau of Economic Research. 
Speculative Hyperinflations in Maximizing Models:

Can We Rule Them Out?

\section{Abstract}

Knife-edge stability is a common property of dynamic monetary models assuming perfect foresight or rational expectations. These models can be closed with the assumption that the economy's equilibrium lies on the unique convergent path (the saddlepath). While this empirically plausible assumption yields sensible results, aggregative models are not specified in sufficient detail to allow one to prove that the saddlepath is the unique equ1librium path. Brock $(1974,1975)$ and Brock and Scheinkman (1980) have advanced models in which individual preferences are more fully specified and in which, under certain conditions, the uniqueness and stability of equilibrium can be rigorously demonstrated. This paper shows that these uniqueness conditions are economically unreasonable. Therefore, the question these maxtmizing models address remains unresolved.

Maurice obstfeld Department of Economics

M.I.T.

Cambridge, MA 02139

(January 1 - June 1, 1982)
Kenneth Rogoff

Division of International Fina Board of Governors of the Federa1 Reserve System Washington, DC 20551

(202) $452-3725$ 
Speculative Hyperinflations In Maximizing Models:

Can We Rule Them Out?

by

Maurice Obstfeld and Kenneth Rogof $f *$

\section{Introduction}

In his seminal papers on monetary perfect-foresight equilibrium, Brock (1974, 1975) asked whether explosive price-level paths can be equilibrium paths when the money supply grows at a constant rate. By deriving the demands for money and goods from the optimizing decistons of infinitely-lived agents, Brock was able to argue that, at least in the conlext of one simple model, such "hyperinflationary equilibria" can be ruled out under a few economically reasonable assumptions. Brock's conclusion have provided an Important theoretical justification for the convergence assumption typically used to close saddlepath-stable macroeconomic models with rational expectations. 1 /

In subsequent work, Brock has modified his earlier conclusions, however. Brock (1978) demonstrates than an additional, less Intuitive, condition is needed to preclude explosive (but not implosive) price paths in a continuous-time version of his discrete-t1me model. Brock and Scheinkruan (1980) prove that a similar condition is necessary to rule out hyperinflationa equilibria in certain overlapping-generations models of money demand. And Scheinkman (1980) does the same in a variant of the Clower (1967) cash-inadvance mode1. These papers are among the few attempts to fustify Ifgorously the stability assumption first proposed by Sargent and Wallace (1973) and now a ublquitous feature of dynamic monetary mode1s. $\frac{2 /}{}$

*/This paper represents the views of the authors and should not be interpreted as reflecting the views of the Board of Governors of the Federal Reserve System. 
Here, we re-exanine and evaluate the assumptions needed to preclude hyperinflationary equilibria in the models of Brock and of Brock and Scheinkman. We establish that the additional condition suggested by Brock (1978) is necessary and sufficient to rule out hyperinflationary equilibria in the discrete-time version of his model, as well as in its continuous-time version. Further, we interpret the condition and show it implies that agents must have infinitely negative utility when their real balances are zero. Unless money is essential in this extreme sense, speculative hyperinflationary paths along which the economy is eventually demonetized are equilibrium paths.

Our results show also that speculative hyperinflation can be ruled out in Brock and Scheinkman's (1980) overlapping-generations econony only if agents, in the absence of money, have infinitely negative utility when old. 


\section{The Brock Model in Discrete Time}

In this section we study a discrete-time version of Brock's (1974, 1975) infinite-horizon dynamic monetary model. The treatment of the model allows the market period length to be an arbitrary, exogenous constant, $h$. The continuous-time model analyzed later may be obtalned as the limit of discrete-time models as $h \rightarrow 0$. A demand for money arises in the model through the assumption that an agent's instantaneous ut1lity depends on his stock of real balances as well as his consumption level. Ilke Brock, we focus on ut1lity functions that are separable. $\frac{3}{\text { / }}$

The model is one in which Identical agents with perfect foresight choose time paths for consumption and nominal money balances that maximize the present discounted value of their instantaneous ut1lity streams. A market period has length $h$, and the Individual must consume at a constant rate $c_{t}$ during each period $t$. The cumulative intra-period ut1lity derived from this consumption is hu(c $\left.c_{t}\right)$. Simllarly, the cumulative intra-period utility derived from holding nominal money balances $M_{t}$ over the period is $h v\left(M_{t} / P_{t}\right)$, where $P_{t}$ is the period-t money price of the single consumption good. The Individual's obfective is thus to maximize

$$
W=\sum_{t=0}^{\infty} h\left[u\left(c_{t}\right)+v\left(M_{t} / P_{t}\right)\right](1-\delta h)^{t / h}
$$

where time, $t$, Is measured in steps of length h. In (1), (1- $-\delta h)$ is the representative agent's fixed subfective inter-perlod discount rate, which naturally depends on the perlod length $h$. The functions $u(\cdot)$ and $v(\cdot)$ are increasing in their respective arguments, strictly concave, and obey the 
Inada conditions

$$
\begin{aligned}
& \lim _{c \rightarrow 0} u^{\prime}(c)=\infty, \\
& \lim _{c \rightarrow \infty} u^{\prime}(c)=0, \\
& \lim _{u \rightarrow 0} v^{\prime}(m)=\infty, \\
& \lim _{m \rightarrow \infty} v^{\prime}(m)=0,
\end{aligned}
$$

where $m$ denotes real balances $M / P$.

At the beginning of each period, a typical individual receives hy units of the consumption good and, from the government, a nominal cash transfer of $\mathrm{H}_{t}$ dollars. Unconsumed units of the consumption good perish at the period's end. The individual's flow budget constraint is therefore given by

$$
M_{t}-M_{t-h}=P_{t} h y-P_{t} h c_{t}+H_{t}
$$

Agents have perfect foresight concerning the future paths of the price level $P_{t}$ and transfers $\mathrm{H}_{t}$, and we therefore do not distinguish, in (3) or below, between actual and anticipated variables.

Let $\lambda_{t}$ denote the Lagrange multiplier associated with constraint (3). The first-order necessary conditions for an optimal individual plan are

$$
\begin{aligned}
& u^{\prime}\left(c_{t}\right)(1-\delta h)^{t / h}=\lambda_{t} P_{t} \\
& -h v^{\prime}\left(M_{t} / P_{t}\right)(1-\delta h)^{t / h}=\left(\lambda_{t+h}-\lambda_{t}\right) P_{t}
\end{aligned}
$$


necessary condition

$$
u^{\prime}\left(c_{t}\right) / P_{t}=h v^{\prime}\left(M_{t} / P_{t}\right) / P_{t}+(l-\delta h) u^{\prime}\left(c_{t+h}\right) / P_{t+h}
$$

whlch summarizes the model's demand side.

Markets are assumed to clear at the beginning of each period. Because the level of government consumption is not directly relevant to the 1ssues discussed here, it is set equal to zero. In equilibrium, the demand for consumption during period $t, h c_{t}$, must equal avallable output hy, and so

$$
c_{t}=y
$$

for all t. Further, the demand for nominal balances must equal the supply, so

$$
M_{t}=M_{t-h}+H_{t}
$$

for all $t$.

By combining the market-clearing conditions (7) and (8) with (6), we obtain a first-order difference equation in $m_{t}$,

$$
\left(B / \sigma_{t}\right) u^{\prime}(y) m_{t+h}=m_{t}\left[u^{\prime}(y)-h v^{\prime}\left(m_{t}\right)\right]
$$

In (9), $B \equiv 1-\delta h$ and $\sigma_{t} \equiv M_{t+h} / M_{t}$. It is assumed that $\sigma_{t}>\beta$ for all $t$. Equation (9) embodies both the first-order conditions of individual optimality (the Euler conditions) and the requirement of market equilibrium. The equation must be satisfied by any equilibrlum path of real balances. Wh1le there are many Euler paths for real balances--paths which satisfy (9)-- 
not all are equilibrium paths. We now discuss a condition under which all but one of these "candidate" equilibria can be ruled out.

\section{The Infeasibility Condition and the Uniqueness of Equilibrium}

By definition, hyperinflationary equilibrium paths are paths along which the price level is unbounded even though the monetary growth rate remains constant. To study the existence of such paths, we assume that $\sigma_{t}$ is constant at level $\sigma .4 /$ This enables us to employ the diagramatic technique Introduced by Brock (1974, 1975). For notational simplicity, the temporary assumption that the period length $h$ equals unity is also made.

Define $A(m) \equiv m^{\prime}\left[u^{\prime}(y)-v^{\prime}(m)\right]$ and $B(m) \equiv m u^{\prime}(y)(\beta / \sigma)$. As shown in Figures $1(a)$ and $1(b)$, the $B(m)$ schedule is a straight line of slope $u^{\prime}(y)(B / \sigma)$ emanating from the origin. If 1 Im $v^{\prime}(m)=\infty$ [assumption $(2 c)$ ], the $A(m)$ schedule may assume elther of the shapes shown in 1 (a) and 1 (b). At the level of real balances $\tilde{m}$ such that $v^{\prime}(\tilde{m})=u^{\prime}(y), A(\tilde{m})=0$. Because $v(\cdot)$ is strictly concave, $A(m), A^{\prime}(m)>0$ for $m>\tilde{m}$ and $A(m)<0$ for $0<m<\tilde{m}$. Provided that $B / \sigma<1, A(m)$ and $B(m)$ Intersect at some $\bar{m}>\tilde{m}$, as shown. $-5 /$ Whether they Intersect at $m=0$ as well depends on the shape of $v(\cdot)$. If $\lim A(m)=$ $-11 m \mathrm{mv}^{\prime}(m)$ equals some strictly negative number, we have the configuration of

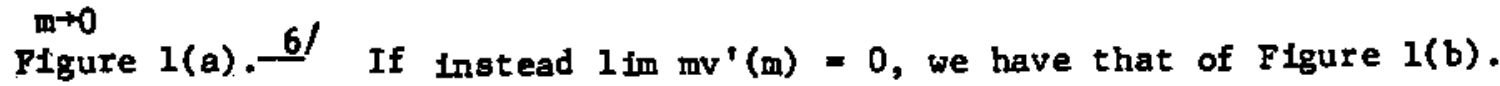
$\mathrm{m} \rightarrow 0$

The Euler equation ( 9 ) may be written as

$$
A\left(m_{t}\right)=B\left(m_{t+1}\right)
$$

The diagram shows how to construct the Euler paths for $m_{t}$, which may be thought of as "candidate" equilibrium paths. Given an Initial $m_{0}, m_{1}$ must 

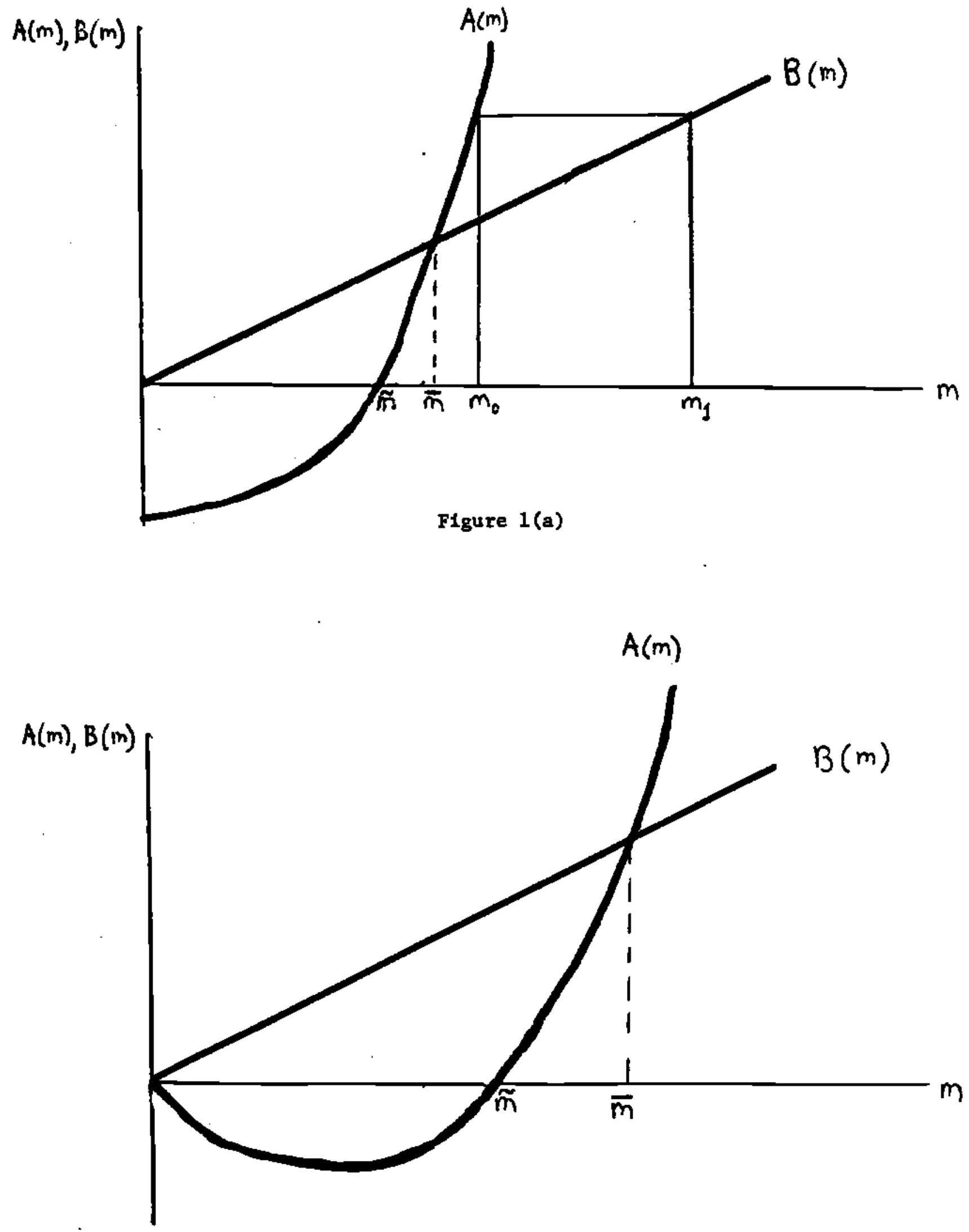

Figure 1(b) 
satisfy $B\left(m_{1}\right)=A\left(m_{0}\right)$, and thus is uniquely determined, as Figure $1(a)$ shows. Using $(10), m_{2}, m_{3}, \ldots$ may be found in the same manner. Although every path generated this way satisfles the necessary conditions of individual optinality and the market-clearing requirement, not every choice $m_{0}$ initiates an equilibrlum path for the economy. Faced with the given path of cash transfers and the implied path of the price level, Individuals may find it advantageous to plan consumption and money-demand paths inconsistent with aggregate intertemporal equilibrium.

The Euler path initlated by $m_{0}=\bar{m}$ is the steady-state path. This path is an equilibrium, for it satisfies the transversality condition

$$
\lim _{t \rightarrow \infty} \beta^{t} u^{\prime}(y) m_{t}=0
$$

which is sufficient for individual optimality. $\frac{7 /}{}$ Existence of a perfectforesight equilibrium is therefore established.

Uniqueness can be established only by ruling out Euler paths that originate to the right or left of $\overline{\mathrm{m}}$. Brock has shown that paths initiated by $m_{0}>\bar{m}$ are not equilibrium if mild conditions are imposed on $v(\cdot)$. [For an alternative discussion, see Gray (1981).] Real balances grow without bound along these paths, and an Individual can always gain by choosing at some point to reduce his real balances forever below the level Indicated by the Euler equation. Consider now paths initiated by $\mathrm{m}_{0}<\overline{\mathrm{m}}$. Along these hyperinflationary paths, real balances decline monotonically over time even though the money growth rate is constant at $\sigma$. We now argue that all such paths may be ruled out as equilibria 1f, and only if, the following infeasibility condition holds:

$$
\underset{m \rightarrow 0}{\lim m v^{\prime}(m)>0 .}
$$


The argument is as follows. First, return to Figure 1(a), which Is drawn on the assumption that (12) does hold. By Inspection, any solution to $(10)$ Initlated by $m_{0}<\bar{m}$ requires that $m_{t}$ eventually become negative. These paths are infeastble, and may therefore be excluded from the class of possible equilibrium paths..$^{8 /}$ It follows that when (12) is valid, the steady-state path is the unique equilibrium path.

When $m v^{\prime}(m) \rightarrow 0$ as $m \rightarrow 0$, as In Flgure $1(b)$, most Euler paths startIng to the left of $\bar{m}$ are again Infeastble. However, Euler paths which pass through $\tilde{m}$, such as the one depicted in Figure 2, are not Infeasible: While the price level becomes and remains infinite after a finite number of periods, real balances need not become negative to generate a path satisfying $(10)$. There exists a countably infinite number of these paths, all of which obey the transversality condition (11) [1n addition to (10)] and and are, in fact, perfect-foresight equilibrium paths. $\frac{9 /}{}$

The nature of these hyperinflationary paths requires comment. First, why do agents hold positive real balances at any time if they expect the price level to become and remain infinite after a fintte number of periods? The reason is that $\tilde{\mathrm{m}}$, the equilibrium real money holding in the period before the price level becomes infinite, satisfies $v^{\prime}(\tilde{m})=u^{\prime}(y)$. Thus, agents are content to hold $\tilde{m}>0$ without attempting to increase consumption above $y$. The utility gained by consuming a dollar just equals that lost through the concomitant reduction in real balances. The Individual is not concerned that his dollars will be worthless next period.

A second question relates to the fact that $v^{\prime}(0)=\infty$. Since the marginal utility of money grows without bound as $m \rightarrow 0$, will it not pay for the Individual at some point to "consume a little less and harvest a large marginal utility from money services"? 


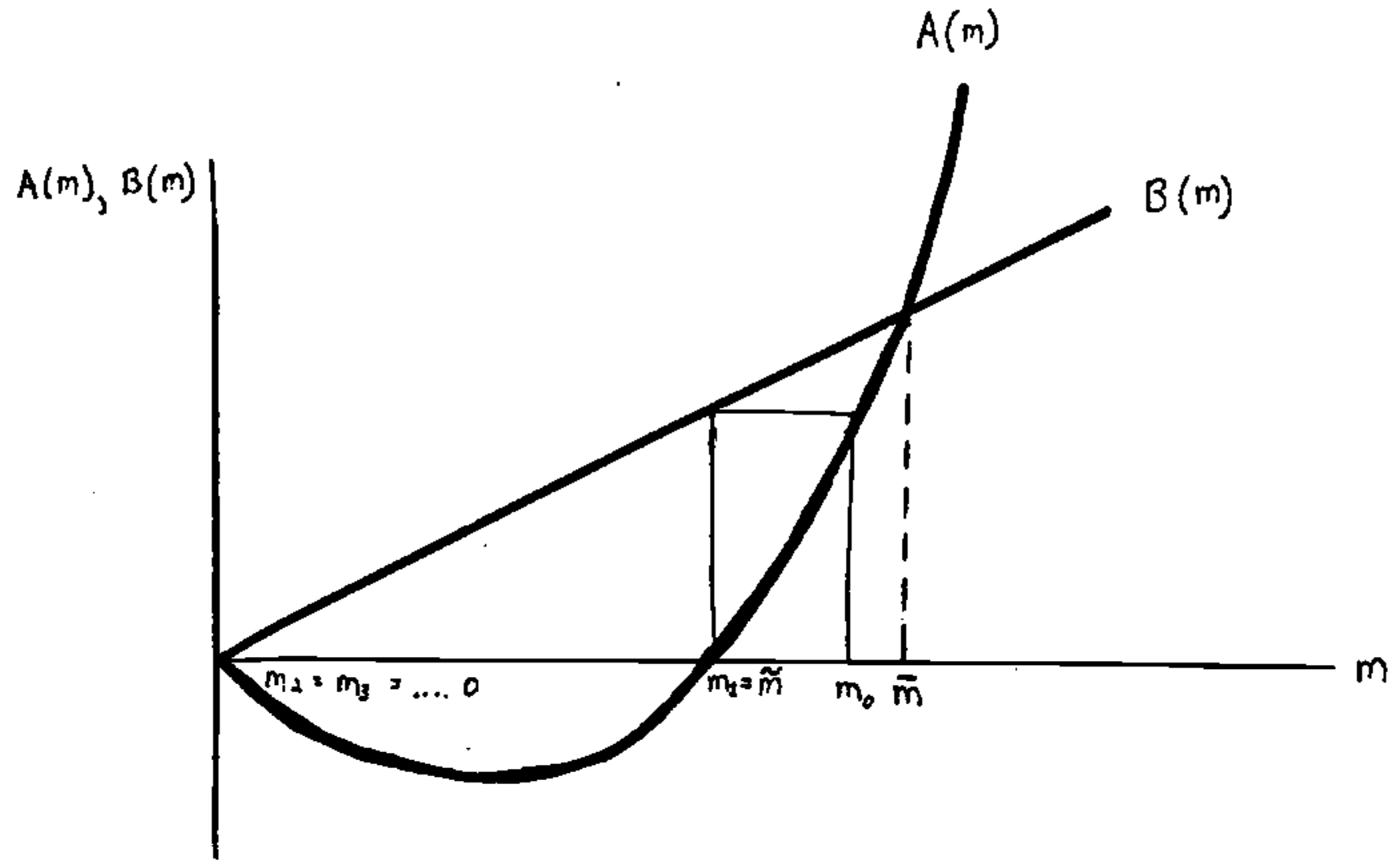

Figure 2 
individual does add a dollar to his money holdings at some time $t$ before the price level jumps to infinity. Two possible strategies bre to consume the dollar before the price level jumps or to hold the dollar forever. Now the first-order condition (6), which must hold along an Euler path, guarantees that for all $n$ with $P_{t+n}<\infty$,

$$
u^{\prime}(y) / P_{t}=\sum_{t=0}^{n-1} \beta^{1} v^{\prime}\left(m_{t+1}\right) / P_{t+1}+\beta^{n} u^{\prime}(y) / P_{t+n^{\prime}}
$$

Thus, the individual cannot gain from strategy one because he is indifferent between consuming a dollar in period $t$ and consuming it in period $t+n$.

Consider strategy two next. If the price level becomes infinite at time $t+T$, then $v^{\prime}\left(m_{t+T-1}\right)=v^{\prime}(\tilde{m})=u^{\prime}(y)$; and by setting $n=T-1$ in the mult period arbitrage condition above, we obtain

$$
u^{\prime}(y) / P_{t}=\sum_{1=0}^{T-1} \beta^{1} v^{\prime}\left(m_{t+1}\right) / P_{t+1}
$$

The gain from holding an extra dollar forever when it is known that money w111 lose its purchasing power at time $t+T$ is given by

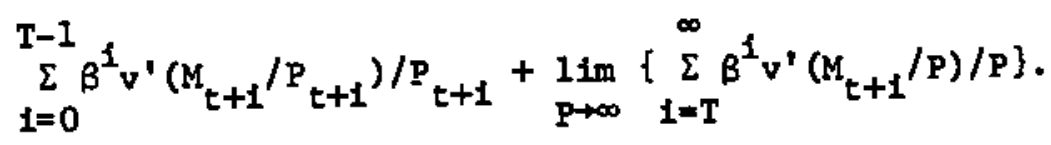

When 1 in $m v^{\prime}(m)=0$, expression (15) equals the right-hand side of (14), and Bo the gain from holding an additional dollar forever just equals the gain from consuming the dollar at time $t$. Therefore, strategy two, like strategy one, cannot augment individual welfare.

A final question is the following: Even when $\lim _{m \rightarrow 0} m^{\prime}(m)>0$, as in Figure $1(a), v^{\prime}(\tilde{m})=u^{\prime}(y)$, so how can we rule out equilibria with $m_{t+T-1}=\tilde{m}$ and $m_{t+T}=m_{t+T+1}=\ldots=0$ Expression (15) shows why the Infeasibility con- 
dition (12) precludes this type of path. First, note that condition (14) is st1ll valid along the path described. But the right-hand side of (14) is now strictly smaller than (15), which is the gain to the individual from adding an extra dollar to his money holdings at time t and holding the dollar forever. Since this gain exceeds the sacrifice $u^{\prime}(y) / P_{t}$ necessary to obtaln the dollar, the hypothetical path we have been considering cannot be equilibrium. The argument makes clear that in a sense, condition (12) implies that money has intrinsic value even when the price level is infinite. We discuss in Section IV whether 1 is reasonable to rule out hyperinflationary equilibria on this basis.

It is worth digressing briefly to note that the problem of hyperInflation does not disappear when agents' 11ves are finite. If $\lim _{\mathrm{m} \rightarrow 0} \mathrm{mv}(\mathrm{m})$ $=0$ and agents choose an InIt1al real-balance level that leads them to hold real balances $\tilde{m}$ at some point before their lives end, the price level will still become infinite in the next period.

We conclude that when the infeasibility condition (12) does not hold, there exist a countable infinity of hyperinflationary Euler paths that cannot be ruled out as equilibria. The next section shows that when trading takes place continuously, there exists a continuum of hyperinflationary equilibria if (12) is false. 
III. The Brock Model in Continuous Time

The previous section's results carry over, with only slight modification, to the continuous-time limit of the discrete-time nodel. $\frac{11 /}{}$ As long as $\lim m v^{\prime}(m)=0$, there exist feasible hyperinflationary equilibrium paths $m \rightarrow 0$ satisfying the Euler equation (10) and the transversality condition (11). We now show that as the market period $h \rightarrow 0$, the set of real-balance levels $\mathrm{m}_{0}$ Intitating a feastble hyperinflationary equilibrium path grows more dense. In the limit of continuous-time trading, any $m_{0}$ lower than the unique steady-state value $\bar{m}$ initiates an equilibrium path when $\lim _{m \rightarrow 0} \mathrm{mv}^{\prime}(\mathrm{m})=$ 0 . When 1 im $m v^{\prime}$ (m) $>0$, the steady-state path remains the sole equilibriur: $\mathbb{I I} \rightarrow 0$ path.

To demonstrate these results, we continue to assume that $\sigma_{t}=\sigma$ for all t. With trading perlod $h$, (9) may be written as

$$
u^{\prime}(y)(1-\delta h)(1-\mu h) m_{t+h}=m_{t}\left[u^{\prime}(y)-h v^{\prime}\left(m_{t}\right)\right] \text {, }
$$

where $\mu \equiv\left(M_{t+h}-M_{t}\right) / h M_{t}=(\sigma-1) / h$ and, by assumption, $\delta, \mu<1$. By $(16)$, the non-zero, steady-state level of real balances $\bar{m}$ solves the equation

$$
v^{\prime}(\bar{m})=u^{\prime}(y)(\delta+\mu-\delta \mu h) .
$$

We now show that when $m_{0}<\bar{m}$, the successive real-balance levels generated by (16) become more closely spaced as $h \rightarrow 0$. Thus, when (12) fails, the set of points $m_{t}$ which lie on some hyperinflationary path becomes more dense as the period length shrinks. For the proof, use (16) to write

$$
m_{t+h} / m_{t} \equiv \theta\left(h, m_{t}\right)=\left\{1-\left[h v^{\prime}\left(m_{t}\right) / u^{\prime}(y)\right]\right\} /[(1-\delta h)(1-\mu h)] .
$$


Since $m_{t}$ falls over time along an explosive price-level path, it must be proved that $\partial \theta / \partial h<0$ for $m_{t}<\bar{m}$. Differentiation of (18) ylelds

$$
\frac{\partial \theta}{\partial h}=\left[v^{\prime}(\tilde{m})-v^{\prime}\left(m_{t}\right)\right] / u^{\prime}(y)+\delta \mu h\left\{\left[h v^{\prime}\left(m_{t}\right) / u^{\prime}(y)\right]-1\right\} .
$$

By (18) and the concavity of $\mathrm{v}(\cdot)$, the foregoing expression is unambiguously negative when $m_{t}<\bar{m}$. Thus, as $h \rightarrow 0$, the distance between $m_{t+h}$ and $m_{t}$ along a feasible Euler path shrinks.

In the limit of continuous time, (16) becomes the differential equation

$$
\dot{m}_{t}=m_{t}\left\{\mu+\delta-\left[v^{\prime}\left(m_{t}\right) / u^{\prime}(y)\right]\right\} .
$$

Figures $3(a)$ and $3(b)$ plot $\dot{m}$ as a function of $m$, with $3(a)$ show $n$ g the case in which condition (12) holds and $3(b)$ the case in which it does not. $\frac{12 /}{\text { It }}$ is evident that $m$ Is $r$ Ising when above the steady-state level $\bar{m}$ and falling when below $\bar{m}$. From $(20)$, $\bar{m}$ is given by the equation $v^{\prime}(\bar{m}) / u^{\prime}(y)=\mu+\delta$. In $3(\mathrm{a})$, any Inttlal $\mathrm{m}_{0}<\overline{\mathrm{m}}$ initlates a path having the property that $\dot{\mathrm{m}}=\lim \left[-\mathrm{mv}(\mathrm{m}) / \mathrm{u}^{\prime}(\mathrm{y})\right]<0$ when $\mathrm{m}=0$. Because $\mathrm{m}$ reaches 0 in finite III 0 time along these paths, Infeasibility allows us to rule them out as before. However, when $1 \mathrm{Im} \mathrm{mv}^{\prime}(\mathrm{m})=0$, as $\ln 3(\mathrm{~b}), \dot{\mathrm{m}} \rightarrow 0$ as $\mathrm{m} \rightarrow 0$. In continuous time, therefore, any $m_{0}<\bar{m}$ in Figure $3(b)$ Initiates a hyperinflationary equilibrium path along which real balances approach zero asymptotically. As in the discrete-time case, the infeasibility condition (12) is necessary and sufficlent to ensure that the steady-state path is the only equilibrium path. 


$$
\text { L }
$$


IV. An Interpretation of the Infeasibility Condition

While the Infeasibility condition (12) Is central to the discussion of "speculative" hyperinflationary equilibria, its interpretali.a remains elustve. It states that an agent holding nominal balances $M$ who adds a dollar to his money holdings reaps a gain $(1 / P) v^{\prime}(M / P)$ which is bounded away from zero no matter how high the price level $\mathrm{P}$. In this sense, condition (12) Implies that money is essential to the welfare of agents.

The nature of this essentlality is made more precise by the following

Theorem. If 1 im $\mathrm{mv}^{\prime}(\mathrm{m})>0$, then $\lim \mathrm{v}(\mathrm{m})=-\infty$.

$$
\text { m } \rightarrow 0
$$$$
m \rightarrow 0
$$

Proof. Let $1 \mathrm{im} \mathrm{mv}^{\prime}(\mathrm{m})=\mathrm{a}>0$, and suppose, contrary to the assertion of the $\mathrm{m}^{\rightarrow 0}$

Theoren, that $v(0)$ is finite. Since $v(\cdot)$ is strictly concave.

$$
v(m)-v(0)>m v^{\prime}(m)
$$

for any $m>0$. Choose $m^{*}$ to be small enough that $v\left(m^{*}\right)-v(0)<E$ and $\left|\mathrm{m}^{*} \mathrm{v}^{\prime}\left(\mathrm{m}^{*}\right)-\mathrm{a}\right|<\epsilon$, where $\varepsilon \leq \mathrm{a} / 2$. Then, by $(21), \varepsilon>\mathrm{v}\left(\mathrm{m}^{*}\right)-\mathrm{v}(0)>\mathrm{m}^{*} \mathrm{v}^{\prime}\left(\mathrm{m}^{*}\right)$ $>a-\varepsilon$. But the foregoing string of inequalities implies that $E>a / 2$ and so contradicts the assumption that $\varepsilon \leq a / 2$. It follows that $v(0)$ cannot be finite, that 1s, there is no positive $m^{*}$ small enough that $v\left(m^{*}\right)-v(0)<\varepsilon$.

According to the Theorem, a utility-of-money function satisfying the infeasibility condition (12) has the property that $v(0)=-\infty$. The converse is not true, however. Any concave function $v(\cdot)$ such that $v(m)=$ $[\log (m)]^{1 / 3}$ for $m \leq \exp (-2 / 3)$ has the property that $v(0)=-\infty$, but aiso satisfies $11 \mathrm{~m} m v^{\prime}(m)=0$. Thus, the assumption $v(0)=-\infty$ is necessary, but not sufficient, to preclude hyperinflationary equilibria. 
The Theorem shows how important money must be if hyperinflationary equilibria are to be excluded. It must be true that if an agent is deprived of his real balances, no finite increase in his endowment of the consumption good can restore him to his previous utility level. This requirement seems inconsistent with the view that the utility-of-money function $v(\cdot)$ captures money's role in reducing the frictions that would characterize a complex barter economy. 14 /

As was shown in Section III, the infeasibility condition (12) excludes hyperinflationary equilibria by ensuring, in effect, that money has some intrinsic value even when the price level is infinite. Starr (1980) points out that "the economy is effectively demonetized when the price of money is zero so that monetary transactions--available at any positive price--are discontinuously unavailable at a null price." If there is a discontinuity in agents' opportunity sets at $P=\infty$, the 1 imit of $\mathrm{mv}^{\prime}(\mathrm{m})$ as m $\rightarrow 0$ becomes economically irrelevant. On this view, it is of doubtful validity to rule out hyperinflationary equilibria in the Brock model even by appealing to condition (12). 
v. Hyperinflationary Equilibria in an Overlapping-Generations Economy

The Infeasibility condition (12) that $\lim _{m \rightarrow 0} \mathrm{mv}^{\prime}(\mathrm{m})>0$ is formally Identical to a condition Brock and Scheinkman (1980) have used to rule out hyperinflationary equilibrla in certain overlapping-generations nodels of money demand. The condition they use refers, however, to the function giving the utility of old-age consumption.

To derive the Brock-Schelnkman condition, consider an economy with a stationary population in which agents live for two periods. Two generations, the "young" and the "old," coexist at each date t. Each agent recelves $y$ units of perishable output while young but none while old. Only by accumulating money in youth can an Individual consume in old age.

The 11fetime ut1lity of an agent young at date $t$ is given by

$$
W\left(c_{t}^{1}, c_{t+1}^{2}\right)=u\left(c_{t}^{1}\right)+\beta u\left(c_{t+1}^{2}\right),
$$

where $c_{t}^{1}$ is his consumption while young and $c_{t+1}^{2}$ his consumption while old. The constraints facing this agent are:

$$
\begin{aligned}
& y-c_{t}^{1}=M_{t} / P_{t} \\
& c_{t+1}^{2}=M_{t} / P_{t+1}+H_{t+1} / P_{t+1}
\end{aligned}
$$

In (23), $\mathrm{t}_{t+1}$ denotes cash transfers from the government, bestowed exclustue$1 y$ on agents old at date $t+1$.

Under perfect foresight, Individual utility maximization implies that 


$$
u^{\prime}\left(c_{t}^{1}\right) / u^{\prime}\left(c_{t+1}^{2}\right)=B P_{t} / P_{t+1}
$$

at an interior maximum. Equilibrium at each date in the goods and money markets implies that

$$
c_{t}^{1}+c_{t}^{2}=y
$$

and that

$$
M_{t}=M_{t-1}+H_{t}
$$

for a11 $t \geq 0$. By (22) and (26), $c_{t}^{1}=y-m_{t}$, where $m_{t}=M_{t} / P_{t}$. A1so, $c_{t+1}^{2}=$ ${ }^{m_{t+1}}{ }$ by (23) and (25). Thus, in equilibrium,

$$
u^{\prime}\left(y-m_{t}\right) / u^{\prime}\left(m_{t+1}\right)=B P_{t} / P_{t+1}
$$

Denoting $M_{t+1} / M_{t}$ by $\sigma(>B)$, we may write (27) as a difference-equation in $m$,

$$
m_{t} u^{\prime}\left(y-m_{t}\right)=(B / \sigma) u^{\prime}\left(m_{t+1}\right) m_{t+1}{ }^{*}
$$

If money is held, the foregoing difference equation must govern the economy's evolution in perfect-foresight equilibrium. $\frac{15 /}{\text { The stationary }}$ state $\bar{m}$ defined by $u^{\prime}(y-\bar{m})=(B / \sigma) u^{\prime}(\bar{m})$ clearly provides one equilibrium. Can there exist, in addition, hyperinflat tonary equilibria along which $m_{t}+$ 0 ? To answer this question, note that as $m_{t} \rightarrow 0$, the left-hand side of (28) approaches zero as we11. As Brock and Scheinkman (1980) observe, however, if 
$11 \mathrm{~m} \mathrm{mu}^{\prime}(\mathrm{m})>0$,

$m \rightarrow 0$

the right-hand side of (28) is bounded away from zero as $m_{t} \rightarrow 0$. Condition (29) is therefore sufficient to rule out hyperinflationary equilibria in this overlapping-generations economy.

The inequality (29) is formally identical to (12), which precludes hyperinflationary equilibria in the Brock model. In particular, the result of section IV shows that in order to rule out hyperinflationary paths for the overlapping-generations economy, it must be assumed that $u(0)=-\infty$. This assumption seems more plausible than the assumption $v(0)=-\infty$ needed to rule out explosive price-level paths in the Brock model.

It should be noted, however, that (29) does not rule out hyperinflations if, say, because of government lump-sum redistribution of endownents, an old agent's income is $\varepsilon>0$ instead of zero. In this case, the difference equation (28) becomes

$$
m_{t} u^{\prime}\left(y-\varepsilon-m_{t}\right)=(\beta / \sigma) u^{\prime}\left(\varepsilon+m_{t+1}\right) m_{t+1} \text {, }
$$

and the right-hand side of (30) goes to zero as $m_{t} \rightarrow 0$ even if (29) holds. Thus, while (29) may be a reasonable assumption, it will exclude hyperinflationary equilibria only in extreme cases. 


\section{Concluding Remarks}

Dynamic monetary models assuming rational expectations or perfect foresight occupy a central position in modern macroeconomics. Because expectations are self-fulfilling in these models, there are many "candidate" equilibrium price levels, each corresponding to a different expected inflation rate. When a model is well-behaved, exactly one expected inflation rate can be justifled exclusively in terms of market fundamentals, that is, the expected future values of (and possibly past innovations in) the exogenous varlables driving the economy. The corresponding price Is sald to lie on the convergent manifold of the system. All others initiate price paths that are fueled in part by speculative anticipations unrelated to actual market conditions.

In an Influential paper, Sargent and Wallace (1973) demonstrated the intultive appeal of closing perfect-foresight monetary models with the assumption that equilibrium prices lie on the convergent manifold. Most subsequent authors have adopted the convergence assumption and have found that it delivers economically sensible results. Nonetheless, there remains the theoretical question of whether any forces guarantee that an economy of maximizing agents will never find 1 tself on a divergent speculative equilibrium path. Wallace (1980), among others, has argued that inconvertible flat money is valued only for 1ts expected future purchasing power and that monetary equilibrium is therefore bound to be "tenuous": The price of money may be zero in equilibrium, and there will exist hyperInflationary equilibrium paths along which money eventually passes out of use.

Brock (1974, 1975), however, provided an infinite-horizon maximizing 
model in which money, while remaining a store of purchasing power, also has an intrinsic value to agents. He modelled this intrinsic value by assuming, with Satuelson (1947), that real balances are an argument in consumers' separable utility functions. The money-in-the-utility-function device was intended to capture money's role in facilftating trarsactions. Brock (1978) subsequently provided a condition on the utility function necessary and sufficient to exclude hyperinflationary equilibria in a continuous-time version of his discrete-time model. A similar condition was found by Brock and Scheinkman (1980) to rule out explosive inflation in a class of overlapping-generations models.

This paper has shown that unless money is essential in the very strong sense that agents have infinitely negative utility without 1 , one cannot rule out hyperinflationary equilibria in Brock's model. This is true in discrete time as well as in continuous time. On the view that money has intrinsic value because it reduces transactions costs, it is implausible to assign it this much importance. In the context of Brock and Scheinkman's (1980) overlapping-generations economy, hyperinflation can be excluded if agents have infinitely negative lifetime utility when old-age consumption is zero. But this is so only if agents have no means of avolding a zero consumption level in old age without holding money. If government lump-sum transfers or "reverse bequests" from children to parents are introduced, speculative equilibrla reappear.

The convergence assumption used to close a wide class of forwardlooking monetary models yields sensible results and has constderable intultive appeal. $16 /$ However, the assumption cannot be rationalized at present by pointing to a simple but more fully specified model of individual behavior 
in which price-level uniqueness can be deduced from the requirements of market equilibrium. Money may be sufficiently essential to preclude hyperinflationary equilibria, but a robust theory demonstrating this has yet to appear. 


\section{Footnotes}

1. See, for example, Lucas (1975), Kour1 (1976), and Rodr1guez (1980).

2. Calvo (1979) studies local uniqueness of equilibriun in models w1th capital. Gray (1981) obtains results similar to Brock's in a model In which money is held because it reduces transactions costs.

3. A number of problems may arise when the utility function $u(c, m)$ is non-separable. In particular, when $u_{\mathrm{cm}}<0$, there may be multiple convergent equilibria even if both goods are everywhere normal. [See Obstfeld (1981).] This paper 1gnores the posstb1lity that there exists more than one convergent equilibrlum path.' It is concerned only wth the possiblifty that an economy possessing a single convergent equilibrium path may also possess divergent equilibrium paths. Calvo (1978, 1979) and Taylor (1977), the latter in the context of an ad hoc molel, describe economies with multiple convergent rational-expectations equilibria.

4. Obstfeld and Rogoff (1981) discuss the implications of a time-varying monetary growth rate.

5. Clearly, $B(\tilde{m})>A(\tilde{m})=0$. Because $B / \sigma<1$ and $v^{\prime \prime}(m)<0$, (2d) ensures that $A(m)$ and $B(m)$ intersect at least once at some $\bar{m}>\tilde{m}$. To show the uniqueness of the steady state $\vec{m}$, write $\Psi(m)=A(m)-B(m)$. It suffices to show that for $m \geq \bar{m}, \Psi^{\prime}(m)>0$. To see this, calculate $\Psi^{\prime}(m)=$ $[1-(B / \sigma)] u^{\prime}(y)-v^{\prime}(m)-m v^{\prime \prime}(m)$. Because $A(\bar{m})=B(\bar{m}), \Psi^{\prime}(\bar{m})=-\bar{m} v^{\prime \prime}(\bar{m})$ $>0$. But for $m>\bar{m},[1-(\beta / \sigma)] u^{\prime}(y)-v^{\prime}(m)>0$, and so $\Psi^{\prime}(m)>0$ for $\mathrm{m} \geq \overline{\mathbf{m}}$. 
6. If $-1 i m m v^{\prime}(m)=-\infty$, the $A(m)$ schedule in Figure $l(a)$ cuts the vertical axis only at $m=-\infty$. This is the case, for example, when $v(m)=m^{1-R} / 1-R$ and $\mathbf{R}>\mathbf{1}$.

7. See Brock $(1974,1975)$ for a proof. To better appreciate the economics of the transversality condition, see the multiperiod version of (6) [equation (13)] developed later in this section and the accompanying discussion [which draws on Gray (1981)].

8. An assumption of free disposability ensures that the price of money can never be negative.

9. It is worth noting that when $\lim _{m \rightarrow 0} v^{\prime}(m)<u^{\prime}(y)$ (contrary to the assumption in the text), the $A(m)$ schedule does not intersect the horizontal axis, but is always above it. In this case, any path originating to the left of $\bar{m}$ is an equilibrium path. Along such a path, the price level approaches infinity asymptotically.

10. In his discrete-time model, Brock (1975), p. 138, uses this argument to rule out hyperinflationary equilibrium paths.

11. The continuous-time limit of the representative household's objective function (1) is

$$
\lim _{h \rightarrow 0} w=\int_{0}^{\infty}\left[u\left(c_{t}\right)+v\left(M_{t} / P_{t}\right)\right] e^{-\delta t} d t
$$

12. This diagram was suggested to us by William Brock. Again, if $\lim _{\mathrm{m} \rightarrow 0} \mathrm{mv}^{\prime}(\mathrm{m})=$ $\infty$, the schedule cuts the vertical axis only at $m=-\infty$. 
13. These hyperinflationary paths are equilibrium because they satisfy the continuous-time transversality condition $\lim _{t \rightarrow \infty} e^{-\delta t^{\prime}} u^{\prime}(y) m_{t}=0$. See Arrow and Kurz (1970) or Brock (1978).

14. Fischer (1974) provides a detailed discussion of the possible roles for real balances in production and utility functions. Brock (1974) also contains a brief discussion of the money-in-the-utility function approach. He shows it is equivalent to assuming that each agent derives utility from consumption and leisure, where leisure is an increasing function of real balances because money saves transactions time. However, this story does not provide a plausible rationalization for the infeasibility condition (12). While it may be reasonable to assume that utility is infinitely negative when leisure is zero, it is not reasonable to assume that an agent who does not hold money will have no leisure time. Gray (1981) specifies a somewhat different role for money, in which real balances reduce the output cost of transactions, rather than their cost in terms of leisure. The condition necessary for uniqueness of equilibrium in Gray's model is formally identical to (12), except that a transactions function replaces the utility-of-money function. The Theorem of Section IV can be used to prove that Gray's uniqueness condition holds only when transactions costs eat up more than one hundred percent of output in the absence of money. Thus, it is impossible to rule out speculative hyperinflations when the demand for money arises from Gray's transactions technology.

15. Of course, nothing precludes the Pareto inefficient nonmonetary equilibrium in which the price of money is zero at all times. If everyone believes money will be worthless next period, it will be in the present model. 
16. In addition, speculative hyperinflations are conspicuously absent from the historical record: Explosive monetary growth seems to be an adequate explanation of all observed hyperinflations. Flood and Garber (1980) subfect this proposition to an econometric test, finding no evidence that the post-World War I German hyperinflation was unjustified in terms of underlying monetary conditions. 


\section{References}

Arrow, Kenneth J., and Kurz, Mordecai. Public Investment, the Rate of Return, and Optimal Fiscal Policy. Baltimore: The Johns Hopkins Press, 1970.

Brock, William A. "Money and Growth: The Case of Long-Run Perfect Foresight." International Economic Review 15, no. 3 (October 1974): 750-777.

Brock, William A. "A Simple Perfect Foresight Monetary Model." Journal of Monetary Economics 1 (April 1975): 133-150.

Brock, William A. "A Note on Hyper-inflationary Equilibria in Long Run Perfect Foresight Monetary Models: A Correction." Mimeo, University of Chicago, 1978.

Brock, William A., and Scheinkman, Jose A. "Some Remarks on Monetary Policy in an Overlapping Generations Mode1." In Models of Monetary Economies, edited by John Kareken and Neil Wallace. Minneapol1s: Federal Reserve Bank of Minneapolis, 1980 .

Ca1vo, Guillermo. "On the Indeterminacy of Interest Rates and Wages with Perfect Foresight." Journal of Economic Theory 19 (December 1978): 321-337.

Calvo, Guillermo. "On Models of Money and Perfect Foresight." International Economic Review 20 (February 1979): 83-103.

Clower, Robert W. "A Reconsideration of the Microfoundations of Monetary Theory." Western Economic Journal 6 (December 1967): 1-8.

Fischer, Stanley. "Money and the Production Function." Economic Inquiry 12, no. 4 (December 1974): 517-533.

Flood, Robert P., and Garber, Peter M. "Market Fundamentals Versus Price-Level Bubbles: The First Tests." Journal of Political Economy 88 , no. 1 (February 1980): 24-58. 
Gray, Jo Anna. "Dynamic Instability in Rational Expectations Models: An Attempt to Clarify." Xerox, Board of Governors of the Federal Reserve System, 1981 .

Kouri, Pentti J.K. "The Exchange Rate and the Balance of Payments in the Short Run and in the Long Run: A Monetary Approach." Scandinavian Journal of Economics 78, no. 2 (May 1976): 280-304.

Lucas, Robert B. Jr. "An Equilibrium Model of the Business Cycle." Journal of Political Economy 83, no. 6 (December 1975):1113-1144.

Obstfeld, Maurice. "Inflation, Real Interest, and the Determinacy of Equilibrium in an Optimizir.g Framework." National Bureau of Economic Research Working Paper no. 723, 1981.

Obstfeld, Maurice, and Rogoff, Kenneth. "Process Consistency in Rational Expectations Models." Xerox, Board of Governors of the Federal Reserv System, 1981.

Rodriguez, Carlos A. "The Role of Trade Flows in Exchange Rate Determinatio A Rational Expectations Approach." Journal of Political Economy BB, no. 6 (December 1980): 1148-1158.

Samuelson, Paul A. Foundations of Economic Analysis. Cambridge: Harvard University Press, 1947.

Sargent, Thomas J, and Wallace, Neil. "The Stabllity of Models of Money and Growth with Perfect ForesIght." Econometrica 41, no. 6 (November 1973): $1043-1048$.

Scheinkman, Jose A. "Discussion." In Models of Monetary Economies, edited by John Kareken and Neil Wallace. Minneapolis: Federal Reserve Bank of Minneapolis, 1980. 
Starr, Ross M. "General Equilibriun Approaches to the Study of Monetary Economies: Comments on Recent Developments." In Models of Monetary Economies, edited by John Kareken and Neil Wallace. Minneapolis: Federal Reserve Bank of Minneapolis, 1980.

Taylor, John B. "Conditions for Unique Solutions in Stochastic Macroeconomic Models with Rational Expectations." Econometrica 45, no. 6 (September 1977): 1377-1385.

Wallace, Neil. "The Overlapping Generations Model of Flat Money." In Models of Monetary Economies, edited by John Kareken and Neil Wallace. Minneapolis: Federal Reserve Bank of Minneapolis, 1980. 